\title{
Disease Evaluation of Existing Tunnel Lining Based on AHP- Extenics
}

\author{
Danhong $\mathrm{Wu}^{1}, \mathrm{Li} \mathrm{Wu}{ }^{1, *}$, Chenyang $\mathrm{Ma}^{1}$, Yufeng Wang ${ }^{1}$, Dexin $\mathrm{Lei}^{1}$, Lin Jia ${ }^{1}$, Jing Wang ${ }^{1}$ \\ ${ }^{1}$ China University of Geosciences, Faculty of Engineering, Wuhan 430074, Hubei, China
}

\begin{abstract}
The existing tunnel lining structure is easily affected by geological conditions, disturbance in the early stage of construction and operation in the later stage. This paper analyzes the main factors affecting the lining structure diseases of existing tunnels from three aspects of engineering construction, natural environment and engineering geology, starting from 13 independent factors affecting the lining structure diseases of existing tunnels. First of all, the index system of the formation factors of lining diseases in the reconstruction and expansion tunnel is established by using the analytic hierarchy process (AHP), and the hierarchical index system is put forward. Based on AHP-Extenics model, the evaluation method of lining structure disease of existing tunnel is proposed. Then, combined with engineering practice and expert scoring, the weight of safety evaluation index is determined, and the safety evaluation index and weight are expanded by using correlation function. Finally, the disease evaluation grade of the existing tunnel lining structure is obtained. This method uses the formal Extenics comprehensive evaluation model, which makes the calculation results more objective and provides a new method for the disease evaluation of the existing tunnel lining structure.
\end{abstract}

\section{Introduction}

With the rapid development of expressway, highway tunnel, as an important part of expressway, has been developed accordingly. More and more highway tunnels are included in the reconstruction and expansion plan. Due to the complexity and particularity of tunnel engineering, a considerable number of existing tunnel lining structures have varying degrees of diseases, threatening traffic safety, affecting traffic quality and service life ${ }^{[1-2]}$.

In recent years, many scholars have studied the classification, causes and safety evaluation of existing tunnel diseases ${ }^{[3-4]}$. Among them, cavity after lining, insufficient lining thickness, improper treatment of surrounding rock and plastic ground pressure are the main reasons for the structural defects of tunnel lining ${ }^{[5]}$. At present, there are few studies on the early disease evaluation of existing tunnel lining structure, and the evaluation method is relatively single ${ }^{[6]}$. AHP-Extenics evaluation model combines the classical AHP method and Extenics theory, replaces the traditional fuzzy comprehensive evaluation method, and provides a new evaluation method ${ }^{[7-8]}$. However, the research and application of this method in the disease evaluation of tunnel lining structure is relatively less, and the evaluation indexes in the existing research results are limited, which can not comprehensively evaluate the disease grade of existing tunnel lining structure ${ }^{[9-10]}$.

In view of this, based on the existing research results, this paper constructs the evaluation index system of the formation factors of tunnel lining structure diseases. Then, through the establishment of AHP-Extenics model, the tunnel lining structure diseases are evaluated by using the calculation results of correlation function and correlation degree. Finally, the model is verified by an engineering example.

\section{Evaluation model of AHP-Extenics}

\subsection{Theoretical basis of evaluation model}

AHP method is an efficient evaluation method which decomposes complex problems into several hierarchies [7]. The n-order judgment matrix of criterion $\boldsymbol{A}$ is shown in Eq. (1).

$$
A=\left(a_{i j}\right)_{n \times n}=\left(\begin{array}{cccc}
a_{11} & a_{12} & \mathrm{~L} & a_{1 n} \\
a_{21} & a_{22} & \mathrm{~L} & a_{2 n} \\
\mathrm{M} & \mathrm{M} & \mathrm{M} & \mathrm{M} \\
a_{n 1} & a_{n 2} & \mathrm{~L} & a_{n n}
\end{array}\right)
$$

Extenics is a theoretical analysis method between classical mathematics and fuzzy mathematics ${ }^{[8]}$. Matter element $(R)$, the logical cells of Extenics, is an ordered triple composed of things $(N)$, features $(c)$ and values $(V)$, as shown in Eq. (2).

$$
R=(N, C, V)
$$

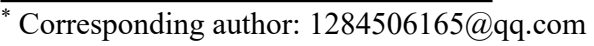


The core of AHP-Extensics model is to use AHP to establish the index system and construct the correlation function combined with Extenics. The process of model is shown in Fig. 1.

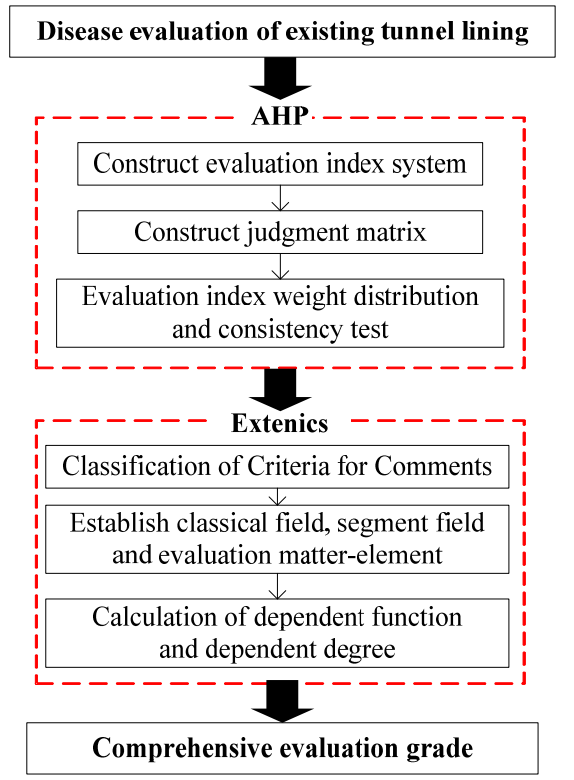

Fig. 1. Process of AHP-Extenics Model.

\subsection{Construction of index system based on AHP}

There are many factors affecting the lining structure diseases of existing tunnels, which can be divided into 3 categories with 13 factors. The evaluation index system as shown in Fig. 2.

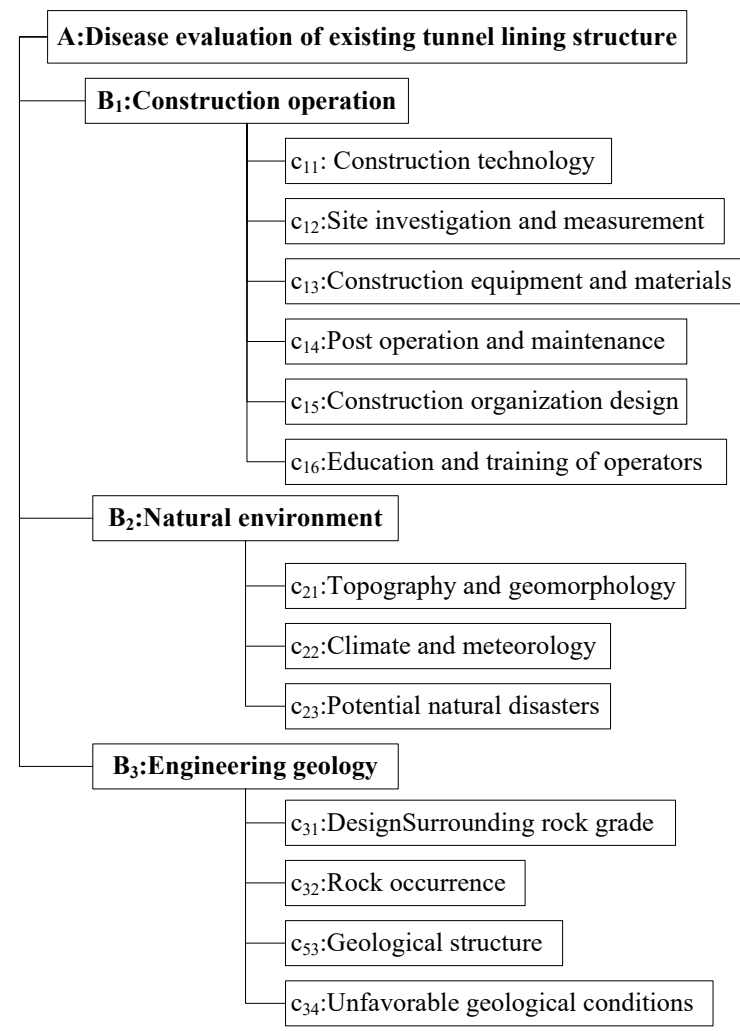

Fig. 2. Disease Evaluation index system of Existing Tunnel
According to Fig.2, AHP metoh is used to construct pairwise judgment matrix and calculate the weight. If $C . R .<0.10$, the consistency test is qualified; otherwise, it should be adjusted ${ }^{[7]}$.

\subsection{Calculation of matter-element based on Extenics}

The existing tunnel lining structure disease evaluation research is set as matter-element $R$, the classical field, the segment field and the evaluation matter-element are given in Eq. (3) Eq. (5) respectively.

$$
\begin{gathered}
R_{U_{i}}=\left(U_{i}, C, V\left(U_{i}\right)\right)=\left[\begin{array}{ccc}
U_{i} & c_{1} & <a_{1}\left(U_{i}\right), b_{1}\left(U_{i}\right)> \\
& c_{2} & <a_{2}\left(U_{i}\right), b_{2}\left(U_{i}\right)> \\
\mathrm{M} & \mathrm{M} \\
& c_{n} & <a_{n}\left(U_{i}\right), b_{n}\left(U_{i}\right)>
\end{array}\right] \\
R_{U}=(U, C, V(U))=\left[\begin{array}{ccc}
U & c_{1} & <a_{1}(U), b_{1}(U)> \\
& c_{2} & <a_{2}(U), b_{2}(U)> \\
\mathrm{M} & & \mathrm{M} \\
c_{n} & <a_{n}(U), b_{n}(U)>
\end{array}\right] \\
R_{p}=(P, C, V(P))=\left[\begin{array}{ccc}
P & c_{1} & V_{1}(P) \\
& c_{2} & V_{2}(P) \\
& \mathrm{M} & \mathrm{M} \\
& c_{n} & V_{n}(P)
\end{array}\right]
\end{gathered}
$$

where $U_{i}$ refers to the level $i, V\left(U_{i}\right)$ refers to the classical field, $U$ refers to all rating levels, $V(U)$ refers to the segment field, $R_{p}$ refers to t evaluation matter-element.

The expression of simple elementary correlation function is given in Eq. (6).

$$
K_{j}\left(v_{k i}\right)=\left\{\begin{array}{cl}
\frac{\rho\left(v_{k i}, V_{0 j i}\right)}{\rho\left(v_{k i}, V_{p i}\right)-\rho\left(v_{k i}, V_{0 j i}\right)} & , v_{k i} \notin V_{0 j i} \\
-2 \frac{\rho\left(v_{k i}, V_{0 j i}\right)}{\left|V_{0 j i}\right|} & , v_{k i} \in V_{0 j i}
\end{array}\right.
$$

where $\rho$ refers to the distance between $x_{0}$ and interval X, as given in Eq. (7).

$$
\rho\left(x_{0}, X\right)=\left|x_{0}-\frac{a+b}{2}\right|-\frac{b-a}{2}= \begin{cases}a-x_{0} & x_{0} \leq \frac{a+b}{2} \\ x_{0}-b & x_{0} \geq \frac{a+b}{2}\end{cases}
$$

The linear method is used to calculate the grade comprehensive correlation degree, see Eq. (8). If $K_{\max }=K_{j}$, the evaluation object belongs to grade $j$.

$$
K_{j}(P)=\sum_{i=1}^{n} W_{i} g K_{j}
$$




\section{Engineering application}

\subsection{Project overview}

Loushan tunnel is a part of the first construction section of Jiaojiang Hongjia Wenling east section of Yinzhou Yuhuan highway. It is a separated tunnel. It is an in-situ expansion of the existing two-way four lane tunnel into a two-way eight lane tunnel. The existing tunnel was completed in 2003 and designed and constructed according to the principle of NATM. The pavement of the new tunnel is located above the pavement of the existing tunnel, and the expanded tunnel is approximately symmetrically excavated relative to the existing tunnel. Due to the complexity and particularity of Loushan tunnel project, it is found that there are different degrees of diseases. The typical diseases on site are shown in Figure 3.
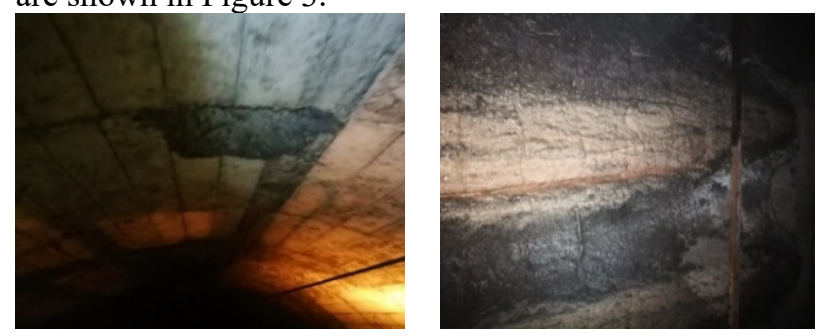

Fig. 3. Typical Diseases in Loushan Tunnel

\subsection{Index weight calculation}

According to Fig. 2, the weight of the damage evaluation index of the lining structure of Loushan tunnel is calculated. According to Eq. (1), the judgment matrix and weight allocation are shown in Table $1 \sim$ Table 4 .

Table 1 A-B judgement matrix and index weight

\begin{tabular}{|c|c|c|c|c|c|}
\hline $\mathbf{A}$ & $\mathbf{B}_{\mathbf{1}}$ & $\mathbf{B}_{\mathbf{2}}$ & $\mathbf{B}_{\mathbf{3}}$ & $\boldsymbol{\omega}$ & Consistency \\
\cline { 1 - 5 } $\mathrm{B}_{1}$ & 1 & 2 & 2 & 0.4938 & \multirow{2}{*}{$\begin{array}{c}\lambda_{\max }=3.00 \\
\text { C.I. }=0 \\
\text { C.R. }=0<0.1\end{array}$} \\
\cline { 1 - 4 } $\mathrm{B}_{2}$ & $1 / 2$ & 1 & $1 / 2$ & 0.1958 & \\
\hline $\mathrm{B}_{3}$ & $1 / 2$ & 2 & 1 & 0.3108 & \\
\hline
\end{tabular}

Table $2 \mathrm{~B}_{1}-\mathrm{C}$ judgement matrix and index weight

\begin{tabular}{|c|c|c|c|c|c|c|c|c|}
\hline $\mathbf{B}_{1}$ & $\mathrm{C}_{11}$ & $\mathrm{C}_{12}$ & $\mathbf{C}_{13}$ & $\mathbf{C}_{14}$ & $\mathbf{C}_{15}$ & $\mathrm{C}_{16}$ & $\omega$ & Consistency \\
\hline $\mathrm{C}_{11}$ & 1 & 8 & 2 & 3 & 5 & 5 & 0.3922 & \multirow{6}{*}{$\begin{array}{c}\lambda_{\max }=6.20 \\
\text { C.I. }=0.04 \\
\text { C.R. }=0.03<0.1\end{array}$} \\
\hline $\mathrm{C}_{12}$ & $1 / 8$ & 1 & $1 / 6$ & $1 / 5$ & $1 / 3$ & $1 / 4$ & 0.0319 & \\
\hline $\mathrm{C}_{13}$ & $1 / 2$ & 6 & 1 & 3 & 5 & 3 & 0.2725 & \\
\hline $\mathrm{C}_{14}$ & $1 / 3$ & 5 & $1 / 3$ & 1 & 3 & 2 & 0.1470 & \\
\hline $\mathrm{C}_{15}$ & $1 / 5$ & 3 & $1 / 5$ & $1 / 3$ & 1 & 1 & 0.0704 & \\
\hline $\mathrm{C}_{16}$ & $1 / 5$ & 4 & $1 / 3$ & $1 / 2$ & 1 & 1 & 0.0860 & \\
\hline
\end{tabular}

Table $3 \mathrm{~B}_{2}$-C judgement matrix and index weight

\begin{tabular}{|c|c|c|c|c|c|}
\hline $\mathbf{B}_{\mathbf{2}}$ & $\mathbf{C}_{\mathbf{2 1}}$ & $\mathbf{C}_{\mathbf{2 2}}$ & $\mathbf{C}_{\mathbf{2 3}}$ & $\boldsymbol{\omega}$ & Consistency \\
\cline { 1 - 5 } $\mathrm{C}_{21}$ & 1 & 1 & 2 & 0.4000 & \multirow{2}{*}{$\begin{array}{c}\lambda_{\max }=3.00 \\
\text { C.I. }=0 \\
\text { C.R. }=0<0.1\end{array}$} \\
\cline { 1 - 4 } $\mathrm{C}_{22}$ & 1 & 1 & 2 & 0.4000 & \multicolumn{1}{|c|}{} \\
\cline { 1 - 4 } $\mathrm{C}_{23}$ & $1 / 2$ & $1 / 2$ & 1 & 0.2000 & \\
\hline
\end{tabular}

Table $4 \mathrm{~B}_{3}$-C judgement matrix and index weight

\begin{tabular}{|c|c|c|c|c|c|c|}
\hline $\mathrm{B}_{3}$ & $\mathrm{C}_{31}$ & $\mathrm{C}_{32}$ & $\mathrm{C}_{33}$ & $\mathrm{C}_{34}$ & $\omega$ & Consistency \\
\hline $\mathrm{C}_{31}$ & 1 & 2 & 3 & 1 & 0.3640 & \multirow{4}{*}{$\begin{array}{c}\lambda_{\max }=4.12 \\
\text { C.I. }=0.05 \\
\text { C.R. }=0.05<0.1\end{array}$} \\
\hline $\mathrm{C}_{32}$ & $1 / 2$ & 1 & 1 & 1 & 0.1956 & \\
\hline $\mathrm{C}_{33}$ & $1 / 3$ & 1 & 1 & $1 / 3$ & 0.1343 & \\
\hline $\mathrm{C}_{34}$ & 1 & 1 & 3 & 1 & 0.3061 & \\
\hline
\end{tabular}

From Table $1 \sim$ Table 4 , the consistency test index $C . R<0.1$, thus the consistency test is qualified. And then, the comprehensive weight of each index can be calculated: $\omega=(0.1937,0.0158,0.1346,0.0726,0.0348$, $0.0425,0.0783,0.0783,0.0392,0.1131,0.0608,0.0417,0.09$ $51)^{\mathrm{T}}$.

\subsection{Comprehensive evaluation of AHP-Extenics}

The lining structure diseases of Loushan tunnel are divided into Very Light $\left(U_{1}\right)$, Mild $\left(U_{2}\right)$, Moderate $\left(U_{3}\right)$, Severe $\left(U_{4}\right)$ and Very Heavy $\left(U_{5}\right)$. According to Eq. (3) $\sim$ Eq. (5), the classical field $V\left(U_{i}\right)$, take criterion layer- $\mathrm{B}_{2}$ as an example, the nodal field matter-element $R_{U}$ and the disease evaluation field matter-element $R_{P}$ are established as followed.

$$
R_{U_{i}}\left(B_{2}\right)=
$$

$$
\begin{aligned}
& V\left(\begin{array}{ccccc}
V\left(U_{1}\right) & V\left(U_{2}\right) & V\left(U_{3}\right) & V\left(U_{4}\right) & V\left(U_{5}\right)
\end{array}\right) \\
& \left.\left.c_{21}\langle 95,100\rangle\langle 85,95\rangle\langle 65,85\rangle<55,65\right\rangle<50,55\right\rangle \\
& \left.\left.c_{22}<95,100\right\rangle<85,95><65,85><55,65\right\rangle \quad<50,55>\text {; } \\
& \left.\left.\left.\left.c_{23}\langle 95,100\rangle<85,95\right\rangle<65,85\right\rangle<55,65\right\rangle<50,55\right\rangle \\
& \left.\left.\left.c_{24}(<95,100\rangle\langle 85,95\rangle\langle 65,85\rangle<55,65\right\rangle<50,55\right\rangle\right)
\end{aligned}
$$

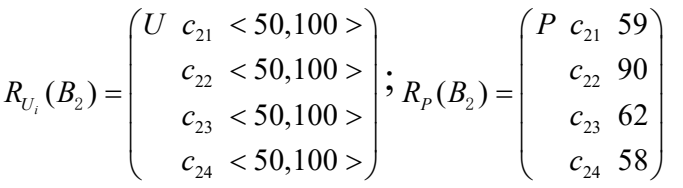

According to Eq. (6) and Eq. (7), the correlation degree $K_{j}$ of layer-C evaluation index can calculated. 


$$
\left.\begin{array}{cc|ccccc} 
& K_{j} & K_{1} & K_{2} & K_{3} & K_{4} & K_{5} \\
C_{11} & -0.8000 & -0.7429 & -0.4000 & -1.2500 & -0.8333 \\
C_{12} & -0.3333 & 1.0000 & -0.3333 & -0.9868 & -0.9906 \\
C_{13} & -0.7333 & -0.6571 & -0.2000 & -1.3235 & -0.9052 \\
C_{14} & -0.8222 & -0.7714 & -0.4667 & -1.3776 & -0.7849 \\
C_{15} & -0.4889 & -0.3429 & 0.5333 & -0.9424 & -0.9736 \\
K_{j}(C)=C_{16} & -0.5111 & -0.3714 & 0.4667 & -0.9320 & -0.9708 \\
C_{21} & -0.4444 & -0.2857 & 0.6667 & -0.9574 & -0.9783 \\
& C_{22} & -0.3077 & 0.8000 & -0.4000 & -0.9883 & -0.9915 \\
& C_{23} & -0.4286 & -0.2000 & 0.3333 & -0.9722 & -0.9831 \\
& C_{31} & -0.3684 & 0.3333 & -0.2000 & -0.9890 & -0.9890 \\
& C_{32} & -0.3913 & 0.0769 & -0.0667 & -0.9875 & -0.9875 \\
& C_{33} & -0.4000 & 0.0000 & 0.0000 & -0.9804 & -0.9868 \\
& C_{34} & -0.7556 & -0.6857 & -0.2667 & -1.2329 & -0.8882
\end{array}\right)
$$

According to Eq. (8), the comprehensive correlation degree of layer-B and layer-A can calculated as followed.

$$
\begin{aligned}
K_{j}(B)= & \begin{array}{c}
K_{j} \\
B_{1} \\
B_{2} \\
B_{3}
\end{array}\left(\begin{array}{ccccc}
K_{1} & K_{2} & K_{3} & K_{4} & K_{5} \\
-0.7235 & -0.6080 & -0.2129 & -1.2314 & -0.8725 \\
-0.3866 & 0.1657 & 0.1733 & -0.9727 & -0.9845 \\
-0.4956 & -0.0735 & -0.1675 & -1.0622 & -0.9575
\end{array}\right) \\
K_{j}(A) & =W_{B} \cdot K_{j}(\mathrm{~B}) \\
& =\left(\begin{array}{lllll}
-0.8822 & 0.0922 & 0.0059 & -2.0349 & -1.9421
\end{array}\right)
\end{aligned}
$$

According to the calculation results of comprehensive correlation degree, the maximum comprehensive correlation degree of target layer-A is $K_{\max }=K_{2}=0.0922$, so the disease evaluation grade of Loushan tunnel lining structure is Mild. Among them, the construction technology and technology, construction equipment and materials and surrounding rock grade have the greatest impact on the tunnel lining structure diseases. It is necessary to strengthen the real-time monitoring and take timely safety prevention and control measures.

\section{Conclusion}

Based on the study of AHP-Extenics model in the disease evaluation of existing tunnel lining, the conclusions are as followed.

(1) According to the 13 independent factors of the existing tunnel lining structure disease evaluation, this paper establishes the existing tunnel lining structure disease evaluation index system by using the analytic hierarchy process from three aspects of construction operation, natural environment and engineering geology, and comprehensively summarizes the influencing factors of the existing tunnel lining structure disease at home and abroad.

(2) According to the theory of extenics, this paper constructs a tunnel lining structure disease evaluation model based on AHP extenics, applies the extension transformation to the tunnel safety evaluation, and puts forward a new tunnel safety evaluation method different from fuzzy mathematics.

(3) By calculating the correlation degree between the index and the evaluation grade, it is determined that the grade of the lining structure disease of Loushan tunnel is Mild. However, due to the great differences between the classical domain and node domain in the calculation of correlation function and correlation degree, the conclusions of this paper need to be further verified.

\section{References}

1. Q. Gao, H. Liu, The construction technology of Qianyangling Tunnel Extenics project. Shanxi Science \& Technology of Communications, 208, 6163 (2011)

2. Q. Chen, Case Study on Widening Options of Jinjishan Tunnel. Tunnel Construction, 31(05), 577$582+592(2011)$

3. Y. Lu, L. Chen, Classification and cause analysis of diseases in existing tunnel. Railway Engineering, 11, 46-49 (2010)

4. S. Zhang, D. Zhang, S. Liu, Discovering the Main Causes of Tunnel Lining Damage Based on Correspondence Analysis Model. China Railway Science, 33(02), 54-58 (2012)

5. C. Wang, M. Lei, L. Peng, Safety evaluation model and method of tunnel disease sturcture. Journal of Railway Science and Engineering, 8(03), 73-77 (2011)

6. J. Hou, Study of Fuzzy comprehensive evaluation method for metro operation safety based on Entropy Weight method. Tunnel Construction, 36(12), 14651470 (2016)

7. B. Liu, S. Xu, H. Zhao, Analytic Hierarchy ProcessTools for Planning and Decision . Systems Engineering, 2, 23-30 (1984)

8. W. Cai, C. Yang, The Application Research, Popularization and Generalization of Extenics. Mathematics in Practice and Theory, 40(07), 214220 (2010)

9. X. Lv, P. Du, H. Zhang, Evaluation and application of expressway construction safety based on Extenics. Hunan Communication Science and Technology, 43(02), 283-287 (2017)

10. L. Qiu, Safety Risk Assessment of Tunnel Rehabilitation Enlargement Based on Matter Element Extenics Model. Tunnel Construction, 38(S2), 25-30 (2018)

11. M. Wang, J. Dong, H. Dong, et al. Novel extension evaluation model for stability of surrounding rock based on connection clouds. Chinese Journal of Geotechnical Engineering, 40(11): 2136-2142 (2018)

12. X. Huang, Q. Chen, Y. Yang, et al. Risk evaluation of karst tunnel under complex geological condition with extension theory. Chinese Journal of Underground Space and Engineering, 9(5): 1179. (2013) 